noted in the hybrids, thereby making it possible to ascertain the possibility of breeding resistant varieties by this method. In connection with these experiments a study of the relative susceptibility of most of the important varieties of Upland cotton is being made, by making actual counts of the bolls naturally infected and by noting the effect of inoculations artificially made.

Boll Weevil Resistance.- Some of the recently introduced Central American varieties which have originated in the region where the boll weevil is native present a series of adaptations which enable them to meet the attacks of this insect with more or less success. These are described in detail by Mr. O. F. Cook, in Bulletin No. 88 of the Bureau of Plant Industry. Mr. R. L. Bennett, of the Bureau of Plant Industry, devoted several years' work to developing early maturing varieties of Upland cotton with a view to securing types which could mature the bulk of their crop before the development of the latest and largest broods of the insect. Mr. F. L. Lewton, also of the Bureau of Plant Industry, has been making selections from the peculiar variety of cotton grown by the Hopi Indians in the southwest, since this exceptionally early maturing and drought-resistant type is well adapted to escape the ravages of the boll weevil. The work of Mr. D. A. Saunders and of the Alabama Experiment Station in breeding with reference to boll-weevil conditions has already been mentioned (pp. 18 and 20).

\title{
LINT INDEX AND LINT PERCENTAGE IN COTTON BREEDING
}

\section{T. H. KEARNEY}

\section{U. S. Department of Agriculture, Washington, D.C.}

It has been the custom of most cotton breeders to use as a criterion for judging productivity, the percentage of lint, i.e., that proportion of the total weight of seed cotton produced by a plant which is represented by the weight of the fiber separated in ginning.

In $1908 \mathrm{Mr}$. O. F. Cook in a paper entitled "Danger in Judging Cotton Varieties by Lint Percentages," issued as circular No. 11, Bureau of Plant Industry, made it clear that this use of lint percentage must often lead to erroneous conclusions. In plants having small light seeds the proportion by weight of fiber to total seed cotton will be relatively high although the actual quantity of fiber produced by the plant may be lower than the average and vice versa. As $\mathrm{Mr}$. Cook (ibid., p. 5) expresses it- 
When the lint percentage is used agriculturally as a basis for estimating the productiveness of a variety the size of the seed must be taken into account, for the same percentage with a large seed means more fiber for the same number of seeds.

As a substitute for lint percentage as a basis for judging productivity, Mr. Cook suggests the use of a "lint index" based upon the weight of fiber borne by a definite number of seeds, 100 being a convenient number. His argument is as follows (ibid., p. 13):

The lint index would give the breeder a far better assurance of superiority than the percentage could ever afford. Reducing the size or weight of the seed would no longer give a variety the misleading advantage that it does by increasing the lint percentage. The chances are fair that the largest amounts of lint will be found on seeds of large size, if not on the largest. At the same time large seeds would not be admitted if the amount of lint were small.

A rather striking illustration of the danger involved in using lint percentage in cotton breeding as a criterion of productiveness recently came to light in the writer's work with Egyptian cotton in the southwest. It was observed during the progress of this work that the lint percentage of the best selections was steadily decreasing from year to year. Thus in a four-acre planting of a very productive variety developed after seven years' of selection from imported seed, the average lint percentage in 1909 was only 27.5, while in Egypt a lint percentage of 33 is commonly obtained. The anxiety caused by this apparently serious decrease in lint percentage was, however, allayed by an observation made by Mr. Argyle McLachlan, who found that in the acclimatized variety the average weight of the seed after removal of the lint was considerably greater than in plants grown from imported seed. The case is thus stated in Bulletin 200, Bureau of Plant Industry, 1910, page 17:

Mr. McLachlan found that imported Mit Afifi seed cotton gave a lint percentage of 33 to 35 and that the delinted seeds weighed only 10 grams per 100 . The acclimatized Yuma variety, which gave only 27.5 per cent of lint, had seeds weighing 13 grams per 100 . If the seeds had weighed no more than imported Mit Afifi seeds the lint percentage of the Yuma variety would have been 33 (a satisfactory percentage for Egyptian cotton) instead of 27.5. Evidently, therefore, no actual diminution in the quantity of lint on the individual seeds has taken place during the process of acclimatization.

The object of the present paper is to throw further light upon the relations between lint percentage, lint index, and weight of seeds upon the basis of results obtained in experiments with Egyptian cotton in 1910. The observations were made upon two sets of material; 
(1) Thirty-eight individual selections in the progeny rows of the Yuma variety of acclimatized Egyptian cotton in the plant-breeding nursery at Sacaton, Ariz.; and (2) seventy-eight samples from a triplicate row variety test of 26 different imported and acclimatized strains and varieties of Egyptian cotton grown at Bard, Cal. In the former case each sample consists of the total product of seed cotton from a singlc individual plant, while in the latter the conclusions are based upon a representative sample from each row of each variety. ${ }^{\mathrm{a}}$

The lint percentage was determined in the ordinary manner by weighing the seed cotton, ginning, weighing the lint after ginning, and dividing the weight of lint by that of seed cotton, the result being checked by weighing also the delinted seed. The average weight of 100 seeds was easily ascertained and from this value the total number of seeds in the sample could be calculated with a probable error of only about 1.0 per cent. The lint index or weight of lint per 100 seeds was calculated by dividing the total weight of ginned fiber in each sample by the estimated total number of seeds and multiplying the quotient by $100 .^{\mathrm{b}}$

Table I gives the range, mean, standard deviation and coefficient of variability of lint percentage, lint index and weight of 100 seeds

TABLE 1.-Summary of observations on acclimated varieties of Egyptian Cotton, with respect to lint percentage, lint index and weight of 100 seeds.

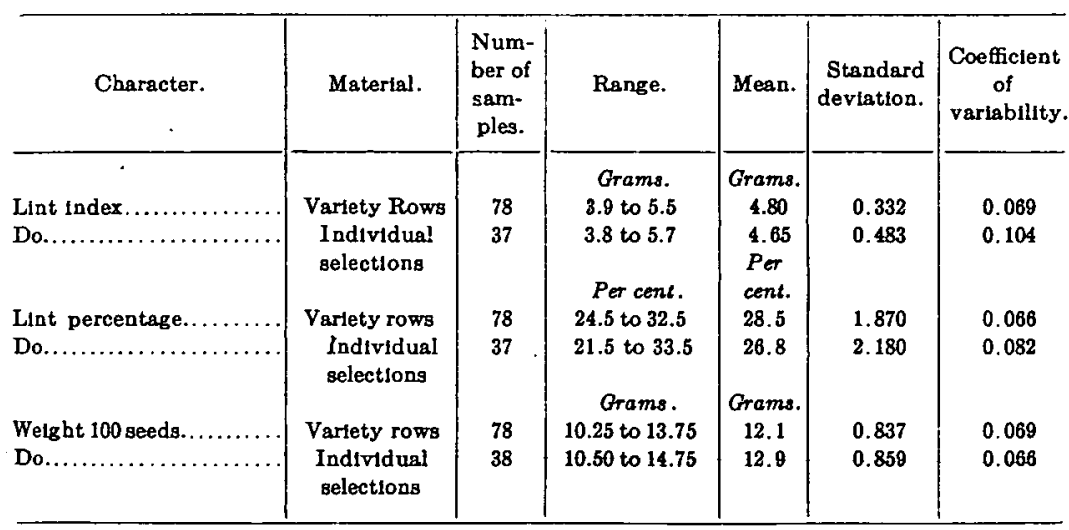

a The sample consisted in each case of one or two bolls from each plant in the row. Owing to lack of unlformity in the soll of the field where this variety test was located, the difference between the different rows of a single variety or strain was of ten as great as that between the different stralns or varieties. Consequently it was deemed best, for the purpose of the following discussion, to treat each row as a unit rather than to average the results from the three rows of each variety.

b On page 14 of the publication above referred to, Mr. Cook suggests a method of calculating the lint Inder from the weight of 100 seeds and the lint percentage as follows: "The lint percentage affords a means of avolding this difficulty without lessening the accuracy of the results, for the weight of the 
in each of the two sets of material. The coefficient of variability was obtained in the usual manner, by dividing the standard deviation by number of samples.

The customary "correlation tables" were then plotted for each set of material in order to bring out such correlations as might exist between the three pairs of characters, lint index and lint percentage, lint percentage and weight of seeds, and lint index and weight of seeds. The tables showed a pronounced positive correlation in the first pair of characters and an evident though less pronounced negative correlation in the second pair, while, as would be expected, the correlation between lint index (weight of lint per 100 seeds) and weight of the seeds themselves was negligible.

The relations of lint index to lint percentage and of lint percentage to weight of seeds of material from the variety rows and individual selections are given in Table 2.

Table 2.-Coefficients of correlation of lint index with lint percentage and of lint percentage with weight of seed per each lot of material (1) and (2).

\begin{tabular}{|c|c|c|c|c|}
\hline Correlation. & Material. & $\begin{array}{c}\text { Number } \\
\text { of } \\
\text { samples. }\end{array}$ & $\begin{array}{c}\text { Coefficient } \\
\text { of } \\
\text { correlation. }\end{array}$ & $\begin{array}{c}\text { Probable } \\
\text { error. }\end{array}$ \\
\hline Lint index $\times$ lint percentage. & Varlety rows & 78 & +0.64 & 0.045 \\
\hline 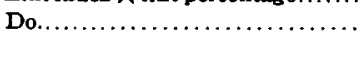 & $\begin{array}{l}\text { Individual } \\
\text { selections }\end{array}$ & $37^{\mathrm{c}}$ & +0.83 & 0033 \\
\hline Llnt percentage $\times$ welght seeds. . & Varlety rows & 78 & -0.63 & 0.46 \\
\hline 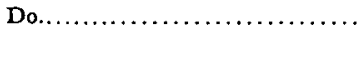 & $\begin{array}{l}\text { Individual } \\
\text { selections }\end{array}$ & 38 & -0.40 & 0.092 \\
\hline
\end{tabular}

It is evident from these results that a lint percentage above the average is usually associated with a weight of lint perindividual seed (lint index) that is also above the average, but the correlation is by no means perfect. As was clearly brought out by the correlation tables from which the coefficients of correlation were calculated, marked exceptions occur. Thus, among the 37 individual selections of the Yuma variety, the highest lint index (5.7) was reached by two plants, one of which gave also by far the highest lint percentage (33.4), while in the other the lint percentage (27.6) was only slightly above the average (26.8) for the 38 plants. On the other hand a plant which

fiber of 100 seeds can easily be calculated after the weight of the seeds and the lint percentage are known. The weight of the hundred seeds divided by the percentage of seed glves the weight of the hundred seeds before ginning. Subtracting the welght of the ginned seeds glves the lint index or welght of the lint of the hundred seeds. With a slide rule it is easier to multiply the welght of the seed by the lint percentage and then divide by the percentage of seed.

c In the case of one of the 38 selections there was some uncertainty about the determination of the lint index, hence it was omitted in calculating the corresponding coefficlent of corrrelation 
gave a relatively high lint percentage (29.4) was considerably below the average in lint index. . Of the 78 samples from the triplicate row variety tests the row which gave the highest lint percentage was inferior in lint index to 14 other rows.

As expressed by the coefficients, the negative correlation between the characters lint percentage and weight of seeds is sufficiently pronounced to indicate that a high percentage of lint is in large measure associated with low weight of seeds. This fact, together with that above noted of marked exceptions to the correlation between high lint percentage and high weight of lint per seed (lint index) makes it clear that, as Mr. Cook has pointed out, the cotton breeder who focuses his attention upon lint percentage as a criterion of productivity... is likely to throw away some of his best plants, saving those which produce small and light seeds but not necessarily the greatest quantity of fiber.

The positive correlation between lint index and lint percentage is much more pronounced among the individual selections of one variety than among the 26 varieties and strains in the row test, while the negative correlation between high lint percentage and high weight of seeds is much less pronounced in the former case than in the latter. It might be inferred from these facts that lint percentage can be used with greater safety as an index of productiveness in comparing individual plants of a fairly uniform variety than in comparing different varieties. But, as above noted, marked exceptions to the correlation between high weight of lint per seed (lint index) and high percentage of lint occur even among the individuals of the single variety. From the standpoint of the practical plant breeder the exceptions are in this case more important than the rule.

\title{
THE RELATION OF CERTAIN EAR CHARAC- TERS TO YIELD IN CORN ${ }^{a}$
}

\author{
H. H. Love
}

Ithaca, New York

One of the very important questions arising in the improvement of corn is, To what extent are visible seed-ear characters correlated with yield? Are there certain characters indicative of high yield which should be kept in mind when seed is being selected?

\footnotetext{
a Paper No. 16, Department of Plant-Breeding Cornell Unlverslty, Ithaca, N. Y.
} 